\title{
PENGUKURAN KEPUASAN PASIEN BERBASIS METODE KEPMENPAN NO. 25 TAHUN 2004
}

\author{
Adila Kasni Astiena $^{1}$, Nur Indrawaty Liputo', Sri Evianti², Dewi Sulistyawati²
}

\begin{abstract}
Abstrak
Rumah Sakit Achmad Mohctar (RSAM) Bukittinggi adalah rumah sakit milik Pemerintah Propinsi Sumatera Barat yang sejak beberapa tahun lalu menerapkan pola pengelolaan keuangan Badan Layanan Umum Daerah (BLUD) yang menuntut adanya akuntabilitas keuangan dan layanan. Dalam KEPMENPAN No. 25/2004 dinyatakan bahwa setiap instansi pemerintah wajib menyelenggarakan survey kepuasan masyarakat. Tujuan penelitian ini adalah untuk mengetahui tingkat kepuasan pasien, kinerja pelayanan, mutu pelayanan dan prioritas peningkatan kualitas pelayanan berdasarkan KEPMENPAN No. 25/2004. Disain penelitian adalah deskriptif kuantitatif. Penelitian dilakukan pada Bulan Mei hingga Juni 2013 di RSAM. Populasi penelitian adalah semua pasien yang datang ke RSAM pada waktu penelitian dilaksanakan. Sampel penelitian 500 orang. Teknik pengambilan sampel Random Block Sampling. Hasil penelitian menunjukkan bahwa semua item pertanyaan dinyatakan valid dan reliabel. Indeks kepuasan pasien adalah 76, mutu pelayanan "B", kinerja unit pelayanan "Baik". Prioritas peningkatan kualitas layanan pada unsur: prosedur pelayanan, persyaratan pelayanan, kedisiplinan petugas, kecepatan pelayanan, keadilan mendapatkan pelayanan, kewajaran biaya, kepastian biaya dan kepastian jadwal pelayanan.
\end{abstract}

Kata kunci: Kepuasan Pasien, Metode Kepmenpan

\begin{abstract}
Ahmad Mochtar Hospital (RSAM) is one of the hospitals owned by West Sumatra Province. RSAM has been implementing financial management strategy of district public service agencies (BLUD) since a few years ago that required financial and service accountability. KEPMENPAN No. 25/2004 states that each public service agency should undergo a public satisfaction survey. The objective of this study is to measure patient satisfaction, service performance, service quality, and the priority of service improvement based on KEPMENPAN method. The design of this study was descriptive quantitative. The population of this study was all patients visiting RSAM from May to June 2013, 500 patients were sampled by Random Block Sampling technique. The result shows that the questionare was valid and reliable. Patient satisfaction index is 76. Most of respondents (74\%) perceived that the quality of service was " $B$ " and the service performance was "Good". Priority of service quality improvement were: service procedures, term of service, disciplinary of service officer, speed of service, service equity, the reasonableness of service charges, the certainty of services cost and schedule. The recommendation for RSAM is to improve the "quality consciousness" culture, by disseminating the results of this survey. Patient satisfaction surveys based on KEPMENPAN is recommended to be held in other hospitals.
\end{abstract}

Keywords: Patient satisfaction, Kepmenpan Method

Affiliasi penulis : Fakultas Kesehatan Masyarakat Universitas Andalas, Korespondensi : Adilla Kasni Astiena, Fakultas Kesehatan Masyarakat, Jl. Perintis Kemerdekaan Padang, email: adila.kasni@yahoo.com, Telp \ HP: 082174422550 


\section{PENDAHULUAN}

Rumah Sakit dr. Achmad Mochtar (RSAM) adalah rumah sakit milik Pemerintah Daerah Propinsi Sumatera Barat. Sejak beberapa tahun yang lalu, RSAM sudah menerapkan pola pengelolaan keuangan Badan Layanan Umum Daerah (BLUD) yang menuntut adanya akuntabilitas keuangan serta akuntabilitas layanan.

RSAM terletak di Bukittinggi mempunyai beberapa pesaing, diantaranya Rumah Sakit Stroke Nasional (RSSN) dan Rumah Sakit Ibnu Sina. Untuk mengantisipasi kebutuhan pelanggan akan layanan kesehatan yang bermutu, RSAM harus memperhatikan kualitas layanan agar tidak ditinggalkan oleh pelanggan.

Keputusan Menteri Pemberdayaan dan Aparatur Negara (KEPMENPAN) no 25 tahun 2004 mewajibkan setiap badan layanan pemerintah untuk menyelenggarakan survey kepuasan masyarakat. ${ }^{1}$ Di samping itu, dalam Keputusan Menteri Kesehatan Republik Indonesia No. 129 Tahun 2008 diatur tentang Standar Pelayanan Minimum Rumah Sakit (SPMRS) yang harus dipenuhi oleh setiap rumah sakit di Indonesia. ${ }^{2}$ Diantara SPMRS tersebut, mengatur tentang kepuasan pelanggan, baik untuk layanan di unit produksi, maupun di unit penunjang. Pada unit produksi, SPMRS kepuasan pelanggan di Instalasi Rawat Jalan adalah 90\%, di Instalasi Rawat Inap $90 \%$, di Instalasi Gawat Darurat $70 \%$, dan di Kamar Bersalin dan Perinatologi $80 \%$. Pada unit penunjang, SPMRS di unit farmasi, laboratorium, dan radiologi masing-masing adalah 80 $\%^{2}$
Parasuraman, Zeithaml dan Berry (1991) dalam Supranto (2011) menyatakan bahwa ada 5 jenis kesenjangan yang dapat mengakibatkan kegagalan dalam penyampaian kualitas jasa. Lima kesenjangan tersebut adalah: ${ }^{3}$

1. Kesenjangan antara harapan konsumen dan persepsi manajemen (manajemen tidak selalu memahami apa yang menjadi keinginan pelanggan).

2. Kesenjangan antara persepsi manajemen dan spesifikasi kualitas jasa (manajemen mungkin benar dalam memahami keinginan pelanggan, namun tidak melaksanakan standar yang spesifik).

3. Kesenjangan antara spesifikasi kualitas jasa dan penyampaian jasa (karyawan pemberi pelayanan mungkin tidak terlatih baik, dan tidak mampu memenuhi standar pelayanan).

4. Kesenjangan antara penyampaian jasa dan komunikasi eksternal (harapan konsumen dibuat oleh wakilwakil dan iklan perusahaan).

5. Kesenjangan antara jasa yang dialami dan jasa yang diharapkan (konsumen mengukur kinerja perusahaan berdasarkan persepsinya yang keliru mengenai kualitas jasa).

Kesenjangan dalam pelayanan jasa di atas, diilustrasikan oleh gambar $1 .{ }^{4}$

Dari sekian banyak gap yang mengakibatkan kegagalan kualitas jasa, maka pemerintah terus berusaha agar pemberian jasa kepada masyarakat terus ditingkatkan kualitasnya sesuai dengan harapan pengguna pelayanan. Terdapat lima determinan kualitas jasa yang dapat dirincikan sebagai berikut: ${ }^{3}$

1. Reliability (Keandalan), yaitu kemampuan untuk melaksanakan 
jasa yang dijanjikan dengan tepat dan terpercaya.

2. Responsiveness (Cepat tanggap), yaitu kemauan untuk membantu pelanggan dan memberikan jasa dengan cepat atau ketanggapan.

3. Assurance (Keyakinan atau jaminan), yaitu pengetahuan dan kesopanan karyawan serta kemampuan mereka untuk menimbulkan kepercayaan atau keyakinan pelanggan.

4. Empathy yaitu syarat untuk peduli, memberi perhatian kepada pelanggan.

5. Tangible (berwujud) yaitu penampilan fasilitas fisik, peralatan, personel dan media komunikasi. ${ }^{3}$

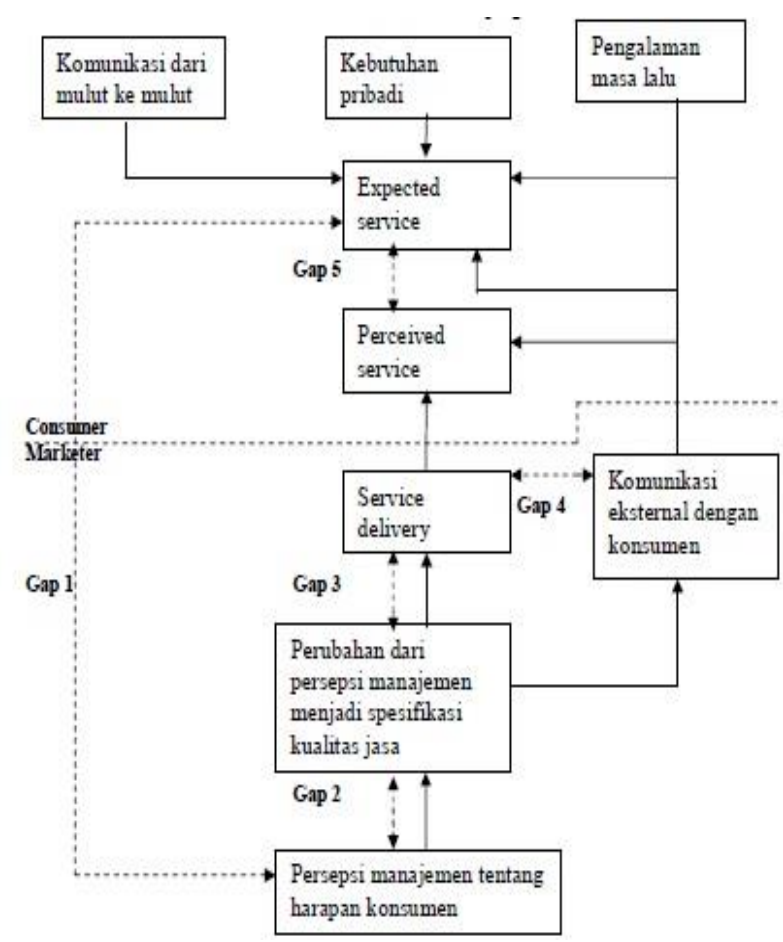

Gambar 1. Berbagai Kesenjangan Da-lam Pelayanan Jasa

Sumber : A. Parasuraman, Valerie A. Zeithmal \& Leonard L. Berry dalam Fandy Tjiptono \& Gregorius Chandra, Service, Quality \& Satisfaction, 2004 dalam Wardhani $(2013)^{4}$
Kepuasan adalah mengenai terlampaunya harapan yang dipunyai pelanggan dibandingkan dengan kualitas layanan yang mereka terima. Seseorang dikatakan puas apabila layanan yang mereka terima melebihi dari yang sebelumnya mereka harapkan. Sebaliknya, pelanggan dikatakan tidak puas apabila harapan mereka tidak terpenuhi, dengan kata lain, nilai kualitas layanan yang mereka terima berada dibawah nilai yang mereka harapkan. ${ }^{3,5}$

Penelitian ini bertujuan untuk mengetahui indeks kepuasan pasien, mutu dan kinerja pelayanan, serta prioritas peningkatan kualitas pelayanan berdasarkan indikator Kepmenpan No. 25 tahun 2004 di RSAM Bukittinggi tahun 2013.

\section{METODE}

Kerangka penelitian ini terlihat pada Gambar 2 yang menjelaskan bahwa penelitian ini mengukur kualitas layanan dengan 14 indikator kepuasan masyarakat sesuai Kepmenpan No 25 Tahun 2004. Kepuasan masyarakat dikategorikan menjadi puas dan tidak puas, kemudian dibandingkan dengan pelaksanaan SPMRS. Selanjutnya dapat ditentukan mutu dan kinerja pelayanan RSAM Bukittinggi secara umum, maupun di tiap instalasi.

Disain penelitian ini adalah deskriptif kuantitatif. ${ }^{6}$ Penelitian dilakukan di RSAM Bukittinggi yang dilaksanakan pada Bulan Mei hingga Juni 2013. Populasi adalah seluruh pasien yang berkunjung ke RSAM dalam periode tersebut. Sampel adalah bagian dari jumlah dan karakteristik yang dimiliki oleh populasi, dimana sampel harus bersifat representatif sehingga kesim- 


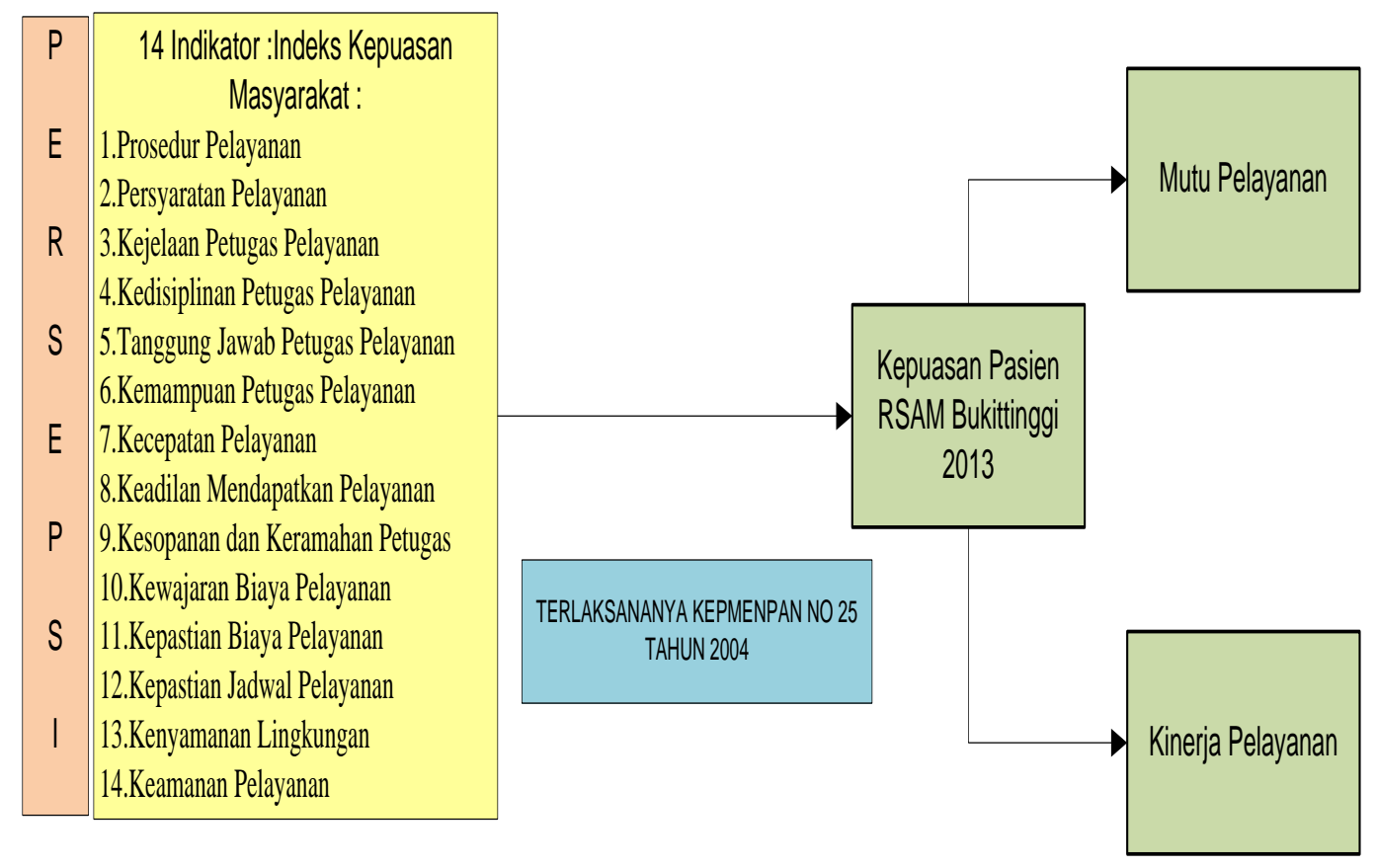

Gambar 2. Kerangka Penelitian

pulan dari sampel tersebut dapat diberlakukan untuk populasi. ${ }^{6}$ Teknik pengambilan sampel pada penelitian ini menggunakan sistem acak / Random Block Sampling yang ditentukan sesuai dengan cakupan instalasi di RSAM Bukittinggi.

Untuk memenuhi akurasi hasil penyusunan indeks, jumlah responden minimal adalah 150 orang dari jumlah populasi penerima pelayanan. Jumlah ini didapatkan dengan menggunakan rumus: jumlah minimal responden $=$ ("Jumlah unsur" + 1) x 10. Jumlah unsur adalah 14 yang merupakan jumlah indikator kepuasan masyarakat berdasarkan Kepmenpan No 25 Tahun 2004. Oleh karena itu jumlah responden minimal adalah $(14+1) \times 10=150$ responden. $^{1}$ Dalam penelitian ini diambil 500 responden dan 10 orang dinyatakan drop out, sehingga jumlah responden adalah 490 orang.
Data primer dikumpulkan dengan menggunakan instrumen kuesioner yang sudah baku sesuai dengan Kepmenpan No 25 Tahun 2004. Cara penilaian terhadap hasil jawaban kuesioner dengan menggunakan rating scale. Responden diminta mengisi pertanyaan dengan memilih salah satu jawaban kualitatif yang sudah dikuantitatifkan. $^{7}$

Tabel 1. Bobot Nilai Jawaban Responden ${ }^{1}$

\begin{tabular}{lc}
\hline Jawaban & Bobot Nilai \\
Responden & \\
\hline Tidak Mudah & 1 \\
Kurang Mudah & 2 \\
MudahSangat & 3 \\
Mudah & 4 \\
\hline Sumber : Kepemnpan No 25 Tahun 2004.
\end{tabular}

Manajemen data dilakukan dengan editing, coding, entry dan analysis data. Analisa dilakukan secara univariat, yaitu dengan cara menggambarkan secara ta- 
bulasi distribusi frekuensi persepsi responden terhadap indikator kepuasan/mutu pelayanan rumah sakit. Selanjutnya ditentukan mutu pelayanan serta kinerja pelayanan rumah sakit serta masing-masing unit/instalasi RSAM Bukittinggi tahun 2013.

Adapun langkah-langkah dalam analisis data adalah sebagai berikut: ${ }^{1}$

1. Menghitung Nilai Rata-Rata Tertimbang dengan cara membagi "jumlah bobot" dengan "jumlah Unsur" pelayanan.

2. Menghitung Nilai Indeks pelayanan dengan cara membagi "Nilai Total dari Persepsi per Unsur" dibagi dengan "Total Unsur Yang Terisi".

3. Menghitung Nilai Indeks Kepuasan Masyarakat (IKM) dalam hal ini Pasien/keluarga dengan cara mengalikan "nilai Indeks" dengan Nilai Penimbang"

4. Mengkonversikan Nilai IKM (Nilai Kepuasan pasien) dengan cara mengalikannya dengan nilai dasar (25).

5. Melakukan penilaian Mutu Pelayanan berdasarkan kategori A,B,C, atau D sesuai dengan tabel 2 .

6. Melakukan penilaian Kinerja Unit Pelayanan (masing-masing Instalasi) berdasarkan kategori : Tidak Baik, Kuarang Baik atau Sangat Baik.

7. Selanjutnya dijelaskan pada tabel 2 berikut ini :
Tabel 2. Kompilasi Nilai Kepuasan Pasien Menjadi Mutu dan Kinerja Pelayanan

\begin{tabular}{lllll}
\hline $\begin{array}{l}\text { Nilai } \\
\text { Per } \\
\text { sepsi }\end{array}$ & $\begin{array}{l}\text { Nilai } \\
\text { Interval } \\
\text { IKM }\end{array}$ & $\begin{array}{l}\text { Nilai } \\
\text { Interval } \\
\text { Konversi } \\
\text { IKM }\end{array}$ & $\begin{array}{l}\text { Mutu } \\
\text { Pelayanan }\end{array}$ & $\begin{array}{l}\text { Kinerja Unit } \\
\text { Pelayanan }\end{array}$ \\
\hline 1 & $1,00-$ & $25-$ & D & Tidak Baik \\
& 1,75 & 43,75 & & \\
\hline 2 & $1,76-$ & $43,76-$ & C & Kurang Baik \\
& 2,50 & 62,50 & & Baik \\
\hline 3 & $2,51-$ & $62,51-$ & B & \\
& 3,25 & 81,25 & & Sangat Baik \\
\hline 4 & $3,26-$ & $81,26-$ & A \\
& 4,00 & 100 & & \\
\hline \multicolumn{5}{c}{ Sumber : Kepmenpan No 25 Tahun 2004. }
\end{tabular}

\section{Definisi Operasional}

Berikut ini dijabarkan pengukuran kepuasan pasien dengan 14 indikator sesuai KEPMENPAN No. 25 Tahun 2005 sebagai berikut :1

\section{Prosedur Pelayanan}

Kemudahan tahapan pelayanan yang diberikan kepada masyarakat dilihat dari sisi kesederhanaan alur pelayanan.

\section{Persyaratan Pelayanan}

Persyaratan teknis dan administratif yang diperlukan untuk mendapatkan pelayanan sesuai dengan jenis pelayanannya.

3. Kejelasan Petugas Pelayanan Keberadaan dan kepastian petugas yang memberikan pelayanan. 
4. Kedisiplinan Petugas Pelayanan

Kesungguhan petugas dalam memberikan pelayanan terutama terhadap konsistensi waktu kerja sesuai ketentuan yang berlaku.

5. Tanggung Jawab Petugas Pelayanan

Kejelasan wewenang dan tanggung jawab petugas dalam penyelenggaraan dan penyelesaian pelayanan.

6. Tanggung Jawab Petugas Pelayanan

Kejelasan wewenang dan tanggung jawab petugas dalam penyelenggaraan dan penyelesaian pelayanan.

\section{Kecepatan Pelayanan}

Target waktu pelayanan dapat diselesaikan dalam waktu yang telah ditentukan oleh unit penyelenggara pelayanan.

8. Keadilan Mendapatkan Pelayanan Pelaksanaan Pelayanan dengan tidak membedakan golongan/status masyarakat (pasien) yang dilayani.

9. Kesopanan dan Keramahan Petugas

Sikap dan perilaku petugas dalam memberikan pelayanan kepada masyarakat secara sopan dan ramah serta saling menghargai dan menghormati.

10. Kewajaran Biaya Pelayanan

Keterjangkauan masyarakat terhadap besarnya biaya yang ditetapkan oleh unit pelayanan.

11. Kepastian Biaya Pelayanan Kesesuaian antara biaya yang dibayarkan dengan biaya yang telah ditetapkan.

12. Kepastian Jadwal Pelayanan

Ketepatan pelaksanaan waktu pelayanan sesuai dengan ketentuan yang telah ditetapkan.

\section{Kenyamanan Lingkungan}

Kondisi sarana dan prasarana pelayanan yang bersih, rapi dan teratur sehingga dapat memberikan rasa nyaman kepada penerima layanan.

14. Keamanan Pelayanan

Terjaminnya tingkat keamanan lingkungan unit penyelenggara pelayanan ataupun sarana yang digunakan, sehingga masyarakat merasa tenang untuk mendapatkan pelayanan terhadap resiko-resiko yang diakibatkan dari pelaksanaan pelayanan.

\section{HASIL DAN PEMBAHASAN}

Sebelum pelaksanaan penelitian, dilakukan terlebih dahulu uji coba kuesioner yang diolah dengan menggunakan program Microsoft Excel for Windows $2007^{8}$, untuk melihat validitas dan reliabilitas kuesioner kepmenpan yang akan digunakan. Validitas diuji dengan rumus Pearson Product Moment dengan kaidah keputusan; jika hasil thitung $>$ ttabel, berarti valid. Reliabilitas diuji dengan rumus Alpha Cronbach, dengan kaidah keputusan; jika hasil rhitung $>$ rtabel, berarti reliabel. Hasil uji validitas dan reliabilitas kuesioner diperlihatkan oleh tabel 3.

Tabel 3. Memperlihatkan bahwa semua pertanyaan pada kuesioner dinyatakan "valid". Nilai Cronbach Alpha adalah 0.87, sehingga semua item pertanyaan tersebut dinyatakan reliabel. Bila Nilai Cronbach Alpha > 0,6 maka kuesioner dinyatakan reliabel. 
Tabel 3. Hasil Uji Validitas dan Reliabilitas Kuesioner Kepmenpan

\begin{tabular}{|c|c|c|c|c|}
\hline $\begin{array}{l}\text { Item } \\
\text { Perta- } \\
\text { nyaan }\end{array}$ & r-Korelasi & Ket & $\begin{array}{l}\text { Cronbach } \\
\text { Alpha }\end{array}$ & Ket \\
\hline $\mathrm{P} 1$ & 0,590 & Valid & \multirow{14}{*}{0,87} & \multirow{14}{*}{ Reliabel } \\
\hline $\mathrm{P} 2$ & 0,564 & Valid & & \\
\hline P3 & 0,646 & Valid & & \\
\hline $\mathrm{P} 4$ & 0,636 & Valid & & \\
\hline $\mathrm{P} 5$ & 0,663 & Valid & & \\
\hline P6 & 0,571 & Valid & & \\
\hline P7 & 0,641 & Valid & & \\
\hline P8 & 0,634 & Valid & & \\
\hline P9 & 0,670 & Valid & & \\
\hline $\mathrm{P} 10$ & 0,574 & Valid & & \\
\hline $\mathrm{P} 11$ & 0,611 & Valid & & \\
\hline $\mathrm{P} 12$ & 0,652 & Valid & & \\
\hline $\mathrm{P} 13$ & 0,640 & Valid & & \\
\hline P14 & 0,597 & Valid & & \\
\hline
\end{tabular}

Berikut ini ditampilkan karakteristik responden antara lain, umur, jenis kelamin, pendidikan, dan pekerjaan $(n=490)$ seperti digambarkan oleh tabeltabel berikut ini.

Tabel 4. Distribusi Responden Menurut Umur

\begin{tabular}{lll}
\hline \multicolumn{1}{c}{ Umur } & Jumlah & (\%) \\
\hline Muda ( $\leq$ 55 Tahun) & 400 & 82 \\
Tua (> 55 Tahun) & 90 & 18 \\
\hline Total & 490 & 100,0 \\
\hline
\end{tabular}

Dari tabel 4 terlihat bahwa sebagian besar (82\%) responden berusia muda ( $\leq 55$ Tahun).

Tabel 5. Distribusi Responden Menurut Jenis Kelamin

\begin{tabular}{lll}
\hline Jenis Kelamin & Jumlah & (\%) \\
\hline Laki-Laki & 181 & 36,9 \\
Perempuan & 309 & 63,1 \\
\hline Total & 490 & 100,0 \\
\hline
\end{tabular}

Dari tabel 5 terlihat bahwa sebagian besar responden berjenis kelamin perempuan (63\%).

Tabel 6. Distribusi Responden Berdasarkan Tingkat Pendidikan

\begin{tabular}{lll}
\hline $\begin{array}{l}\text { Tingkat } \\
\text { Pendidikan }\end{array}$ & Jumlah & (\%) \\
\hline SD ke Bawah & 45 & 9,2 \\
SLTP & 70 & 14,3 \\
SLTA & 213 & 43,5 \\
D1, D3, D4 & 46 & 9,4 \\
S1 & 106 & 21,6 \\
S2 ke atas & 10 & 2,0 \\
\hline Total & 490 & 100,0 \\
\hline
\end{tabular}

Dari tabel 6 terlihat bahwa sebagian besar (44\%) responden berpendidikan SLTA.

Tabel 7. Distribusi Responden Berdasarkan Jenis Pekerjaan

\begin{tabular}{lll}
\hline $\begin{array}{c}\text { Jenis } \\
\text { Pekerjaan }\end{array}$ & Jumlah & (\%) \\
\hline PNS/TNI/POLRI & 101 & 20,6 \\
Pegawai Swasta & 75 & 15,3 \\
Wiraswasta/Usahawan & 130 & 26,5 \\
Pelajar/Mahasiswa & 38 & 7,8 \\
Lainnya & 146 & 29,8 \\
\hline Total & 490 & 100,0 \\
\hline
\end{tabular}

Dari tabel 7 terlihat bahwa sebagian besar responden mempunyai pekerjaan pada kategori "lainnya" (30\%).

Indeks kepuasan pasien, mutu dan kinerja pelayanan di RSAM tahun 2013, diperlihatkan oleh tabel-tabel berikut ini. 
Tabel 8. Distribusi Pendapat Responden terhadap 14 Indikator Kepuasan di RSAM 2013

\begin{tabular}{|c|c|c|c|}
\hline No & $\begin{array}{l}\text { Unsur } \\
\text { Pelayanan }\end{array}$ & $\begin{array}{l}\text { Nilai Unsur } \\
\text { Pelayanan }\end{array}$ & $\begin{array}{l}\text { Nilai } \\
\text { Indeks } \\
\text { per } \\
\text { item }\end{array}$ \\
\hline 1. & $\begin{array}{l}\text { Prosedur } \\
\text { pelayanan }\end{array}$ & 3,01 & 0,21 \\
\hline 2. & $\begin{array}{l}\text { Persyaratan } \\
\text { Pelayanan }\end{array}$ & 3,07 & 0,22 \\
\hline 3. & $\begin{array}{l}\text { Kejelasan } \\
\text { Petugas } \\
\text { pelayanan }\end{array}$ & 3,10 & 0,22 \\
\hline 4. & $\begin{array}{l}\text { Kedisiplinan } \\
\text { petugas } \\
\text { pelayanan }\end{array}$ & 3,10 & 0,22 \\
\hline 5. & $\begin{array}{l}\text { Tanggung jawab } \\
\text { petugas } \\
\text { pelayanan }\end{array}$ & 3,13 & 0,22 \\
\hline 6. & $\begin{array}{l}\text { Kemampuan } \\
\text { petugas } \\
\text { pelayanan }\end{array}$ & 3,15 & 0,22 \\
\hline 7. & $\begin{array}{l}\text { Kecepatan } \\
\text { pelayanan }\end{array}$ & 2,96 & 0,21 \\
\hline 8. & $\begin{array}{l}\text { Keadilan } \\
\text { mendapatkan } \\
\text { pelayanan } \\
\end{array}$ & 3,06 & 0,22 \\
\hline 9. & $\begin{array}{ll}\text { Kesopanan } & \text { dan } \\
\text { keramahan } & \\
\text { petugas } & \end{array}$ & 3,11 & 0,22 \\
\hline 10. & $\begin{array}{ll}\text { Kewajaran biaya } \\
\text { pelayanan }\end{array}$ & 3,05 & 0,22 \\
\hline 11. & $\begin{array}{l}\text { Kepastian biaya } \\
\text { pelayanan }\end{array}$ & 2,97 & 0,21 \\
\hline 12. & $\begin{array}{l}\text { Kepastian jadwal } \\
\text { pelayanan }\end{array}$ & 2,96 & 0,21 \\
\hline 13. & $\begin{array}{l}\text { Kenyamanan } \\
\text { lingkungan }\end{array}$ & 3,08 & 0,22 \\
\hline 14. & $\begin{array}{l}\text { Keamanan } \\
\text { pelayanan }\end{array}$ & 3,14 & 0,22 \\
\hline & Total & & 3,04 \\
\hline
\end{tabular}

Dari tabel 8, didapatkan nilai indeks 3,04. Setelah dikonversi dengan nilai dasar yaitu 25, maka didapatkan nilai indeks kepuasan masyarakat secara umum di RSAM Bukittinggi adalah 76 . Dengan demikian didapatkan mutu pela- yanan pada kategori $\mathrm{B}$, artinya, kinerja unit pelayanan "Baik". Kecepatan Pelayanan, kepastian Jadwal pelayanan serta Kepastian Biaya Pelayanan merupakan tiga indikator yang memiliki nilai terendah.

Layanan kesehatan yang bermutu merupakan suatu kebutuhan masyarakat yang harus diselenggarakan RSAM dengan cara yang sopan, santun, tepat waktu, tanggap dan mampu menyembuhkan pasien secara lahir batin. Pandangan pasien terhadap mutu layanan ini sangat penting karena pasien yang merasa puas, akan mematuhi pengobatan dan bersedia untuk datang kembali bila merasa sakit. Sesungguhnya tujuan akhir dari pelayanan rumah sakit adalah kepuasan pasien (patient satisfaction) yang berkaitan dengan bebas dari penyakit atau kecacatan, dan kesesuaian pembiayaannya. ${ }^{9}$

Kepuasan pada pasien berbeda dengan kepuasan pengguna jasa lainnya seperti hotel. Kepuasan pada pasien menuntut hal-hal yang terkadang belum tentu sesuai dengan harapannya, walaupun petugas pemberi layanan sudah memberikan pelayanan sebagaimana mestinya. Hal ini karena pasien/keluarga datang ke rumah sakit dalam keadaan kondisi fisik dan psikis yang kurang baik (cemas, khawatir, ketakutan), berbeda sebaliknya dengan tamu yang menginap di hotel. Pasien tidak hanya sekedar membutuhkan sopan, santun, keramahan dan kenyamanan seperti halnya di hotel, namun juga membutuhkan kompetensi klinis, kecakapan, teknik, cepat tanggap, disamping juga kepastian jadwal pelayanan dan kepastian biaya pelayanan. ${ }^{9}$ Dalam hubungannya dengan tabel 8, kepuasan pasien di RSAM su- 
dah dinilai baik oleh pelanggan (pasien/ keluarga).

Pendapat responden tentang mutu serta kinerja pelayanan RSAM ditampilkan pada tabel 9.

Tabel 9. Distribusi Frekuensi Penilaian Responden Terhadap Mutu / Kinerja Pelayanan

\begin{tabular}{lll}
\hline Mutu/Penilaian Kinerja & F & (\%) \\
\hline Mutu A/ Kinerja sangat baik & 109 & 22 \\
Mutu B/ Kinerja Baik & 363 & 74 \\
Mutu C/ Kinerja Kurang & 18 & 4 \\
Mutu D / Kinerja Tidak Baik & 0 & 0 \\
\hline Total Responden & 490 & 100 \\
\hline
\end{tabular}

Dari tabel 9 terlihat bahwa sebagian besar $(74 \%)$ responden mempunyai penilaian "mutu B". Pasien merasa puas dan menilai "mutu B", artinya kinerja pelayanan secara umum di RSAM Bukittinggi juga dikatakan "Baik". Tidak satupun pasien yang menilai mutu layanan "D" atau kinerja layanan "Tidak Baik". Hal ini perlu dipertahankan oleh RSAM, dan hendaknya terus ditingkatkan di masa yang akan datang.

RSAM harus memahami status kesehatan masyarakat dan kebutuhan akan layanan kesehatan, sembari terus mendidik masyarakat dan melibatkan masyarakat (pasien dan pengunjung) tentang bagaimana cara efektif untuk menyelenggarakan layanan kesehatan yang bermutu. Dilihat dari perspektif provider (pemberi layanan kesehatan), mutu sering dikaitkan dengan ketersediaan peralatan, prosedur kerja atau protokol, kebebasan profesi dalam melakukan tindakan layanan medis/-keperawatan sesuai dengan teknologi kesehatan mutakhir. Sementara mutu dari perspektif masyarakat tidak akan mampu menilai kompetensi teknis dan tidak mungkin mengetahui layanan kesehatan apa yang mereka butuhkan. ${ }^{10}$ Bagi mereka layanan kesehatan yang bermutu adalah kemampuan rumah sakit untuk memuaskan persepsi atau keinginan mereka (kepuasan pasien). Gap inilah yang hendaknya diisi oleh RSAM, sehingga perlu dibangun suatu hubungan yang saling percaya antara masyarakat dengan penyelenggara layanan kesehatan. Dengan demikian, berbagai indikator mutu sesuai dengan persepsi pasien hendaknya dapat diselenggarakan oleh rumah sakit. ${ }^{9}$

\section{SIMPULAN}

Metode Kepmenpan No.25 Tahun 2004 layak dijadikan sebagai metode alternatif pengukuran kepuasan pasien (non servqual) di rumah sakit.

Dari hasil Survey Kepuasan Pasien di Rumah Sakit Achmad Mochtar Bukittinggi tahun 2013, maka disimpulkan bahwa indeks kepuasan pasien terhadap pelayanan RSAM adalah 76, persepsi masyarakat terhadap mutu pelayanan "B" dan Kinerja Pelayanan "Baik". Unsur pelayanan yang harus diprioritaskan di RSAM yaitu kecepatan pelayanan, kepastian jadwal pelayanan serta kepastian biaya pelayanan.

Dari penelitian yang dilakukan, maka dapat disarankan agar RSAM meningkatkan budaya "sadar" mutu dengan cara lebih mensosialisasikan lagi standar pelayanan minimum (SPM) Rumah Sakit dalam pertemuan formal dan informal, disamping itu perlu dilakukan audit mutu internal secara berkala.

Disamping Kepuasan Pasien, hendaknya penelitian lain terkait SPM 
lainnya dapat diselenggarakan, antara lain waktu tunggu pelayanan, kelengkapan pengisian dokumen, angka infeksi nosokomial, kepastian tidak adanya kejadian kesalahan tindakan medik/ keperawatan serta kesalahan dalam pemberian obat sesuai dengan instalasi yang di survey.

\section{DAFTAR RUJUKAN}

1. Keputusan Menteri Pemberdayaan dan Aparatur Negara No. 25 Tahun 2004, (2004).

2. Keputusan Menteri Kesehatan Republik Indonesia No. 129 Tahun 2008, (2008).

3. Supranto J. Pengukuran Tingkat Kepuasan Pelanggan Untuk Menaikkan Pangsa Pasar. Jakarta; Rineka Cipta 2011.

4. Wardani EK. Pengukuran Tingkat Kepuasan Konsumen Jasa Penerbangan (Studi Kasus Pada Jasa Penerbangan Garuda Indonesia Semarang - Jakarta). Jurnal Studi Manajemen dan Organisasi 2006;3(1):4063.
5. Naomi P. Pengukuran Tingkat Kepuasan Pelanggan Terhadap Jasa Pelayanan Kesehatan, diunduh 7 Desember 2013, dari:http.www.jurnal.upi.edu

6. Notoatmodjo S. Metodologi Penelitian Kesehatan. Jakarta; Rineka Cipta 2003.

7. Sugiyono. Metode Penelitian Kuantitatif, Kualitatif, dan R\&D. Bandung; Alfabeta 2008.

8. Astiena AK. Hubungan Kepemimpinan Senior, Tata Kelola dan Tanggung Jawab Sosial Terhadap Kinerja kepala Ruang Rawat Inap di Rumah Sakit Karya Bhakti Bogor. Thesis FKM Universitas Indonesia 2009.

9. Wijono D. Manajemen Mutu Rumah Sakit dan Kepuasan Pasien, Prinsip dan Praktek. Surabaya; Airlangga 2008

10. Pohan IS. Jaminan Mutu Layanan Kesehatan, Dasar-Dasar Pengertian dan Penerapan. Jakarta; EGC 2007.

11. Liputo NI, Astiena AK. Laporan Penelitian Survey Kepuasan Pelanggan Rumah Sakit Dr. Achmad Mochtar Bukittinggi Tahap I, Tahun 2013, Laporan Penelitian. Tidak dipublikasikan. 